\title{
The Effect of Contraceptive Knowledge on Fertility: The Roles of Mass Media and Social Networks
}

\author{
Kai-Wen Cheng
}

Published online: 4 February 2011

(C) The Author(s) 2011. This article is published with open access at Springerlink.com

\begin{abstract}
This study examines the effect of contraceptive knowledge on fertility during the period when Taiwan's family planning programs were in effect. This study contributes to previous studies by directly measuring individual's contraceptive knowledge and fertility, as well as applying an instrumental variable approach to gauge the effect of contraceptive knowledge on fertility. The results indicate that mass media and social networks play important roles in disseminating contraceptive knowledge. This study finds that women transform their knowledge into behavior-that is, contraceptive knowledge reduces fertility, no matter which fertility metric is measured (life-time fertility or probability of giving birth).
\end{abstract}

Keywords Contraceptive knowledge - Family planning · Fertility

\section{Introduction}

Many advertising campaigns sponsored by private or public agencies disseminate health, nutrition, and product information aimed at changing people's behaviors. Such information about issues reaches its goal only if individuals obtain the disseminated information and transform the acquired information into new behaviors. This study focuses on the period when Taiwan's family planning programs were in effect and examines the relationship between contraceptive knowledge and fertility. It examines

\section{K.-W. Cheng $(\bowtie)$}

Center for Tobacco Control Research and Education, University

of California San Francisco, 530 Parnassus Ave, \#366,

San Francisco, CA 94143-1390, USA

e-mail: kai-wen.cheng@ucsf.edu associations between socio-demographic factors and the knowledge about contraceptive techniques introduced from the programs; influences of the mass media exposure and social network on the acquisition of that contraceptive knowledge; and whether the obtained contraceptive knowledge reduces fertility.

The implementation of family planning programs is an example of providing information intended to change behaviors. In Lapham and Mauldin (1985), they provided a framework for understanding the role of program effort in the conditions of fertility decline. The first component of the effort is activities in providing information about contraceptive techniques as well as population concerns to women of childbearing age which aims to increase the practice of contraception and thus, control fertility. The ultimate aim of family planning programs is to couple low birth rates with a consistently low mortality rate to reduce population growth. For developing countries where the population transitions from a combination of high mortality rate and high birth rate to a combination of low mortality rate and high birth rate, the resulting rapid population growth may create pressures on housing, education, and social patterns. Such a situation often dramatically increases the financial burden of the nation as a whole. In order to control population growth by reducing fertility rates, governments may opt to implement family planning programs which provide married couples with information about modern contraceptive techniques, contraceptive access, and the benefits of having fewer children. In some societies, such programs may also aim to overcome entrenched gender preference toward sons, for example in Taiwan, China, and South Korea (Chang et al. 1981; Freedman et al. 1974, 1994).

Several studies have focused on investigating whether such family planning programs play any role in decreasing 
fertility, or the decrease is reflected by the reduced demand for children driven by economic and social changes (For example, Gertler and Molyneaux 1994; Hondroyiannis 2010; Miller 2009; Pritchett 1994; Shreffler et al. 2010; Sinha 2005). Indeed, the endogenous characteristics of the input-allocation of family planning programs-high fertility villages tend to be the target of family planning programs and hence receive more family planning inputs than other areas-make the evaluation of the effect of family planning programs challenging (Rosenzweig and Wolpin 1986; Schultz 1994, 2005).

This study examines the factors related to the acquisition of contraceptive knowledge, and the relationship between individuals' contraceptive knowledge and their fertility during the period when family planning programs were enacted. This study contributes to previous studies examining the effectiveness of family planning programs on fertility by (1) focusing on individuals' obtained contraceptive knowledge and fertility, and (2) applying an instrumental variable approach to investigate the effect of contraceptive knowledge on fertility. Since dissemination of information relating to modern contraceptive techniques is one of the main ways for family planning programs to control fertility (Lapham and Mauldin 1985; Montgomery and Casterline 1993), examining the influences of individual characteristics, mass media exposure, and social networks on the acquisition of the contraceptive knowledge from the programs and the subsequent effects on fertility shed new lights on the effectiveness of family planning programs, as well as the relationship between contraceptive knowledge and fertility.

Indeed, the obtained contraceptive knowledge is jointly determined by factors related to the demand- and supplyside of contraceptive knowledge. Unobserved factors, such as a couple's modernization and their sex/quantity preference toward children, determine the levels of demand for both fertility and contraceptive knowledge (Rosenzweig and Schultz 1989). The existence of unobserved factors makes identification of causality challenging. This study uses an instrumental variable approach to resolve the endogeneity issue. Mass media exposure and connection to social networks are treated as instrumental variables of contraceptive knowledge to examine the effect of contraceptive knowledge on fertility.

This paper is structured as follows: Second section presents the background of "Taiwan's family planning programs". Third section contains the "Literature review". Fourth section introduces the "Data" that this paper uses and basic summary statistics. Fifth section contains the "Identification strategy". Sixth section presents the "Results". Seventh section evaluates "Limitation and evaluation of our instrumental variables". Eighth section concludes the "Conclusion" of the study.

\section{Taiwan's Family Planning Programs}

Taiwan's death rate fell from about 14 to 5 per thousand between 1948 and 1962, while the fertility rate remained unchanged. High fertility rates and low death rates led to an annual rate of population growth that reached $3.5 \%$ in the years between 1951 and 1956. The 3.5\% growth rate caused the population to double in only 20 years (Freedman and Takeshita 1969). Therefore, Taiwan's family planning programs were implemented to slow down population growth and shorten the period of demographic transition to prevent a large population growth that might impede economic development.

Taiwan's family planning programs, enacted in 1964, aimed to decrease the fertility rate in order to control population growth. To reach this goal, the programs educated citizens about population growth issues, extolled the benefits of smaller families and valuing daughters as highly as sons, and provided information about accessing and using contraceptive techniques (Chang et al. 1981, 1987; Freedman et al. 1974; Sun et al. 1978). In Taiwan in the 1960s, primary education was not universal and both public transportation and communication technologies were limited; the family planning program therefore used a variety of information dispersal techniques, including visiting families, placing advertisements/announcements in mass media, and encouraging word-of-mouth communication via friends, relatives, or neighbors to disseminate the information on family planning programs (Chu 1966; Freedman et al. 1994; Sun et al. 1978). For example, the information about modern contraceptive techniques, modern contraceptive access, and the benefits of having fewer children.

The program involved 300 female health workers who made motivational and educational visits to women of childbearing age in their homes to offer subsidized contraceptives (Freedman et al. 1994). Since the number of pre-pregnancy health workers was limited, they concentrated first on visiting families with more than three children, those with sons, those living in high-fertility counties, the poor, and those living in remote villages (Chu 1966; Sun et al. 1978). The family planning programs also used public media, such as radio, TV, newspapers, and slides at Taiwan's movie houses to explain contraceptive techniques and how to obtain contraceptives. Articles on family planning were published every month from 15 of Taiwan's 22 newspapers; in 1965 there were a total of 319 articles related to family planning; around 50,000 posters were printed and placed in villages around the island ( $\mathrm{Chu}$ 1966). Mass media and word-of-mouth communication are the main ways to disseminate the contraceptive information (Montgomery and Casterline 1993). About $60 \%$ of married women indicate they obtained the information about family 
planning from mass media or friends/relatives/neighbors (Coombs 1973). The government also used financial incentives to encourage women to use contraception. When new kinds of contraceptive techniques were introduced, the government updated their method of subsidizing contraceptives. The government first encouraged using loop and subsidized half of the cost; then they started to encourage using contraceptive pills and condoms and subsidized part of the cost. In addition to the government's subsidization of sterilization surgery for the poor, each city government also used welfare funding to subsidize sterilization surgery for the general population (Freedman et al. 1994). The number of people undergoing surgical sterilization rose rapidly.

\section{Literature Review}

There have been several studies investigating the relationship between knowledge and behaviors that have focused on different fields of interest, such as consumption and health-related behaviors. Some studies measure an individual's information acquisition about issues and examine the individual's subsequent behavior according to different information acquisition (for example, Chang et al. 2010; Kan and Tsai 2004; Kenkel 1991; Variyam et al. 1999); others focus on an event shock, such as the removal of the ban on nutrition claims on product and advertising style campaigns, to identify the information effect to examine different reactions among different subgroups toward the new information (for example, de Walque 2007; Ippolito and Mathios 1990).

Regarding the literature about factors related to fertility, there is a large body of literature, covering several different countries, investigating the relationship between contraception and fertility. Most of this literature focuses on contraceptive accessibility and availability rather than knowledge (For example, Braunder-Otto et al. 2007; Gertler and Molyneaux 1994; Miller 2009; Sinha 2005). In addition, a large body of literature has focused on the individual's decision to use (or not to use) contraception and their choice of contraception types focusing on institutional and social factors influencing the decisions (for example, Behrman et al. 2002; Edmeades 2008). Institutional factors shape the accessibility and availability of contraceptives which directly influence the use and choice of contraception (Braunder-Otto et al. 2007). Social effects, on the other hand, influence contraceptive adoption through defining it as a social acceptable behavior, and by spreading the information and adoption of new behaviors (Behrman et al. 2002; Edmeades 2008; Montgomery and Casterline 1993). Institutional effects and social effects may jointly influence the adoption of new behaviors. Institutional effects may indirectly influence the new behavior by establishing a social and economic environment which relates to the diffusion and adoption of new behaviors (Edmeades 2008).

The institutional effects and social effects influence the dissemination of contraceptive knowledge in the same way that they influence contraceptive practice and choice. The mass media campaigns/advertisements sponsored by family planning programs could be seen as an institutional effect because they directly influence women's awareness of modern contraceptives, not only by spreading information about contraceptive methods, but also by identifying locations for obtaining contraceptives. These campaigns can also be seen as social effects, as they shape contraception as a social acceptable behavior. Social networks, through which the contraceptive knowledge spread, are another method by which a social effect influences the establishment of contraceptive knowledge and multiplies the effect of mass media on the build of contraceptive knowledge. Several studies focus on factors such as mass media and social networks, associating them with the establishment of health-related information (Aggarwal and Rous 2006; Barber and Axinn 2004; Behrman et al. 2002; Kan and Tsai 2004; Montgomery and Casterline 1993). This study adds to the existing literature by examining the effect of contraceptive knowledge obtained from several mechanisms, such as mass media and social networks, on fertility.

\section{Data}

This research is primarily based on data from island-wide surveys, "Knowledge, Attitudes, and Practice of Contraception in Taiwan" (KAP). They are repeated cross-sectional data conducted, respectively, in 1965 (KAP 1), 1967 (KAP 2), 1970 (KAP 3), 1976 (KAP 4), 1980 (KAP 5), 1985 (KAP 6), 1992 (KAP 7), and 1998 (KAP 8). This study uses KAP 1, 2, 4, 5, and 6 closest to the reform in 1964, and excludes the KAP 3 survey because its nature is different from the other sets of KAP. KAP 3 re-interviewed half of the respondents interviewed in 1967, while the other half of the data is from an independent sample in the 22-39 age cohorts. The KAP survey interviewed married women of reproductive age (18-44). The data set includes information about women's fertility history, desired number of children, and attitudes toward, knowledge of, and use of contraception which provides a unique resource to investigate the relationship between contraceptive knowledge and fertility. In addition, measures of socio-economic status and demographic information such as age, education, employment, and family history for both wives and husbands are covered.

Table 1 presents the summary statistics of individual characteristics, contraceptive knowledge and practice, as well as mass media exposure for each survey year. In 1965, 
Table 1 Summary statistics

\begin{tabular}{|c|c|c|c|c|c|}
\hline & $\begin{array}{l}1965 \\
(N=3,719)\end{array}$ & $\begin{array}{l}1967 \\
(N=4,989)\end{array}$ & $\begin{array}{l}1976 \\
(N=5,587)\end{array}$ & $\begin{array}{l}1980 \\
(N=3,852)\end{array}$ & $\begin{array}{l}1985 \\
(N=3,819)\end{array}$ \\
\hline Number of living births & 4.04 & 3.96 & 3.20 & 2.70 & 2.66 \\
\hline Ever had abortion $(\%)$ & 10 & 12 & 20 & 23 & 28 \\
\hline Number of contraceptive techniques known & 3.5 & 4.00 & 6.15 & 8.05 & 7.97 \\
\hline Ever practiced contraception $(\%)$ & 27 & 41 & 68 & 83 & 88 \\
\hline Whether respondent reads newspapers regularly (\%) & 14 & 21 & 29 & 51 & 62 \\
\hline Whether respondent reads magazines regularly (\%) & N/A & N/A & 11 & 16 & 22 \\
\hline Whether respondent listens to the radio regularly (\%) & 55 & 54 & 15 & 27 & 49 \\
\hline Whether respondent watches the TV regularly (\%) & N/A & 21 & 70 & 79 & 93 \\
\hline Whether participate in any organizations (\%) & N/A & N/A & 15 & 6 & 6 \\
\hline Don't have sons (\%) & 18 & 15 & 18 & 20 & 18 \\
\hline \multicolumn{6}{|l|}{ Women's Education level } \\
\hline Illiterate $(\%)$ & 49 & 40 & 25 & 12 & 8 \\
\hline Elementary $(\%)$ & 41 & 49 & 59 & 58 & 48 \\
\hline Junior high $(\%)$ & 6 & 6 & 8 & 11 & 17 \\
\hline Senior high $+(\%)$ & 4 & 5 & 7 & 19 & 27 \\
\hline Live in city $(\%)$ & 30 & 31 & 43 & 47 & 50 \\
\hline Whether working outside of family $(\%)$ & 17 & 20 & 44 & 31 & 33 \\
\hline Whether living with parents or parent's in law (\%) & 52 & 46 & 39 & 38 & 40 \\
\hline Women's age & 31.95 & 32.15 & 33.49 & 30.70 & 32.20 \\
\hline \multicolumn{6}{|l|}{ Contraceptive knowledge } \\
\hline Know condom $(\%)$ & 29 & 30 & 54 & 85 & 89 \\
\hline Know foam tablets $(\%)$ & 29 & 28 & 29 & 36 & 24 \\
\hline Know jelly $(\%)$ & 17 & 15 & 23 & 35 & 26 \\
\hline Know diaphragm (\%) & 12 & 14 & 19 & 35 & 38 \\
\hline Know rhythm (\%) & 20 & 27 & 45 & 60 & 67 \\
\hline Know basic temperature $(\%)$ & 5 & 9 & 20 & 43 & 53 \\
\hline Know coitus interruption $(\%)$ & 4 & 8 & 24 & 45 & 50 \\
\hline Know Ota ring $(\%)$ & 64 & 61 & 76 & 87 & 75 \\
\hline Know loop (\%) & 47 & 62 & 89 & 96 & 92 \\
\hline Know oral pill (\%) & 31 & 47 & 85 & 93 & 93 \\
\hline Know vasectomy (\%) & 33 & 35 & 65 & 93 & 93 \\
\hline Know tubal ligation $(\%)$ & 61 & 63 & 83 & 96 & 96 \\
\hline
\end{tabular}

the year after the nationwide implementation of family planning programs, the women in fertile ages had 4.04 live births on average. In 1967, two years after, the average number of live births dropped to 3.96 and it kept dropping to 2.66 live births in 1985. On the other hand, contraceptive knowledge among married women of fertile age was expanding over time (see Table 1). In 1965, married women knew about 3.5 modern contraceptive techniques on average; in 1967, married women knew about four modern contraceptive techniques, and in 1980s, married women knew about eight modern contraceptive techniques.

The prevalence of each specific technique might reflect the target of contraception that family planning programs emphasize. The loop was first adopted as the primary contraceptive method in 1964, followed by the introduction of oral pill, condom, Ota ring, and sterilization into the programs in 1969, 1970, 1972, 1973, respectively (Chang et al. 1981). Furthermore, the practices of contraception and abortion had been increasing. In 1965, only $27 \%$ of married women ever practiced contraception; however, in $1985,88 \%$ of them ever practiced contraception. In 1965 , only $10 \%$ of married women had ever had an abortion; in $1985,28 \%$ of them had had one or more abortion.

The increasing trends of mass media exposure, women's education levels, urban residence, and women's working status also reflected the rapid social changes and economic development of Taiwan during the 1960-1980s. More and more women were regularly exposed to radio, TV, newspapers, and magazines over time. Women's education levels and working status also increased. 


\section{Identification Strategy}

The direction of causation between contraceptive knowledge and fertility behaviors is a concern. One possibility is that contraception knowledge affect fertility; women who have higher contraceptive knowledge are more resourceful in choosing among different kinds of contraceptive techniques and practice the contraception to control their fertility. Another possibility is that fertility affects the acquisition of contraceptive knowledge. Women who have reached their desired number of children, or have achieved their desired gender ratio among their children, have incentives to seek out more contraceptive knowledge than those who have not. Finally, external factors may determine levels of both fertility and contraceptive knowledge. For example, women who are more "modern" and "westernized" are more open to and resourceful with modern contraceptive techniques, and they at the same time demand fewer children.

Therefore, the ordinary least squares (OLS) model without correcting the endogeneity in contraceptive knowledge, does not gauge the true effect of contraceptive knowledge on fertility. This study used an instrumental variable approach to overcome the endogeneity issue, using mass media exposure and women's participation in organizations as the instruments of contraceptive knowledge. The hypotheses are: (1) married women who regularly listen to the radio, watch TV, read magazines, or read newspapers have more access to contraceptive advertisements and family planning campaigns, and hence, obtain more contraceptive information; (2) married women who actively participate in community-based organizations have a wider social network, and hence, obtain more contraceptive knowledge through word-of-mouth communications. Sect. 7 explains in detail the strength and validity of these instruments.

\section{Life-time Fertility}

First, the OLS model, which does not take into account endogeneity issue, was applied to estimate the life-time fertility Eq. (1) to investigate the relationship between contraceptive knowledge and fertility. $N_{i}$ refers to the number of live births by the woman $i$; $K_{i}$ is the number of contraceptive techniques the woman $i$ has heard of; $X_{i}$ refers to other variables influencing fertility, such as the woman's age cohort, education, husband's education, husband's income, husband's ancestry, her current working status, urban/rural residence, cohabitation with parents-inlaw, and other factors.

$N_{i}=\beta_{0}+\beta_{1} K_{i}+\beta_{2} X_{i}+\varepsilon_{i}$

Second, the endogeneity of contraceptive knowledge was taken into account. In order to overcome the endogeneity issue, the two-stage least square (2SLS) approach was applied: first, mass media exposure and organization participation were used as the instruments to identify the effect of contraceptive knowledge in Eq. (2), and then the predicted value of contraceptive knowledge from (2) was used to estimate the effect of contraceptive knowledge in the fertility Eq. (3). The variables indicating whether the respondents regularly watch $\mathrm{TV}\left(I V 1_{i}\right)$, listen to the radio $\left(I V 2_{i}\right)$, read newspapers $\left(I V 3_{i}\right)$, or read magazines $\left(I V 4_{i}\right)$ are proxies for exposure to the fertilityrelated campaigns and contraceptive advertisements in the mass media. The variable indicating whether they participate in community organizations $\left(I V 5_{i}\right)$ is a proxy for exposure to contraceptive knowledge through social networks (word-of-mouth communication).

$$
\begin{aligned}
K_{i}= & \gamma_{0}+\gamma_{1} I V 1_{i}+\gamma_{2} I V 2_{i}+\gamma_{3} I V 3_{i}+\gamma_{4} I V 4_{i}+\gamma_{5} I V 5_{i} \\
& +\gamma_{6} X_{i}+v_{i}
\end{aligned}
$$

$N_{i}=\beta_{0}+\beta_{1} \hat{K}_{i}+\beta_{2} X_{i}+\varepsilon_{i}$

The Probability of Giving Birth

The number of live births was recorded from the year of marriage to the current year, while contraceptive knowledge, women's working status, urban/rural residence, and cohabitation with parents-in-law, and the measures of mass media exposure and social network were measured in the current year. To ensure the examination of the effect of knowledge on fertility, all variables were measured in the current state. A linear probability model was used to examine the likelihood of giving birth in the previous year in Eq. (4)

$B_{t-1, i}=\beta_{0}+\beta_{1} K_{t, i}+\beta_{2} N_{t-1, i}+\beta_{3}$ Boy $_{t-1, i}+\beta_{4} X_{t, i}+\varepsilon_{i}$

$B_{t-1, i}$ is a binary variable indicating whether the married women had a live birth last year; $K_{t, i}$ is the current contraceptive knowledge; $N_{t-1, i}$ is the number of live births until the last year; $B o y_{t-1, i}$ is the number of boy births until the last year; $X_{t, i}$ refers to other variables influencing fertility, such as the woman's age cohort, education, husband's education, husband's income, husband's ancestry, her current working status, urban/rural residence, cohabitation with parents-in-law, and other factors. OLS model without correcting the endogeneity issue is first estimated.

In addition, the endogeneity of contraceptive knowledge was taken into account and the 2SLS approach was applied. First, mass media exposure and organization participation were used as the instruments to identify the effect of contraceptive knowledge in Eq. (5), and then the predicted value of contraceptive knowledge from (5) was used to estimate the effect of contraceptive knowledge in the 
fertility Eq. (6). The same set of instrumental variable as the total number of live birth equation indicating whether the respondents regularly exposed to mass media and their connections to social networks was used.

$$
\begin{aligned}
K_{i}= & \gamma_{0}+\gamma_{1} I V 1_{i}+\gamma_{2} I V 2_{i}+\gamma_{3} I V 3_{i}+\gamma_{4} I V 4_{i}+\gamma_{5} I V 5_{i} \\
& +\gamma_{6} X_{i}+v_{i}
\end{aligned}
$$

$$
B_{t-1, i}=\beta_{0}+\beta_{1} \hat{K}_{t, i}+\beta_{2} N_{t-1, i}+\beta_{3} \text { Boy }_{t-1, i}+\beta_{4} X_{t, i}+\varepsilon_{i}
$$

\section{Results}

\section{Life-time Fertility Equation}

Table 2 presents the regression results of the number of live births estimated with OLS. The regressions are estimated separately by each survey year. Wife's education level and current working status, which could serve as proxies for prices of having children, are negatively associated with the number of live births. Husband's income is not statistically associated with the number of births.

Older women have more live births than younger ones. Women who live in the city have fewer births. The OLS model indicates that contraceptive knowledge is positively associated with the number of live births in the earlier survey years: 1965, 1967, and 1976. The magnitude of this association decreases with time. The sign of coefficient on contraceptive knowledge changes to negative in the later survey years: 1980 and 1985. The positive relationship between contraceptive knowledge and life time fertility contradicts the intuition that contraception prevents unintended births, since it does not take into account the endogeneity issue. Indeed, the positive relationship explains a possible source of endogeneity: there might be a target effect driving the positive relationship. For example, women with a very large number of children are the target of family planning programs and get more resources from the programs, such as family visits from health personnel, telephone contacts, etc. about the contraceptive knowledge. The decreasing magnitude of positive target effects explains that the target effect has been vanishing over time. Another explanation for the positive relationship is the reverse causality between contraceptive knowledge and fertility: women who have had a large number of births might have more incentives to seek out effective contraceptive techniques on their own to prevent pregnancy. ${ }^{1}$

\footnotetext{
${ }^{1}$ In order to handle the issue of censoring at zero in the distribution of births, a log linear model and a two-part model are estimated for the life time fertility equation. The results are consistent with the findings in the paper.
}

In order to resolve the endogeneity issue, a 2SLS model which takes into account endogeneity is estimated. Table 3 presents the results. The result of IVs from the first stage is listed in the upper panel of Table 3 , and the second stage in the lower panel of Table 3. The result from first stage indicates that women who are regularly exposed to mass media, including watching $\mathrm{TV}$, listening to the radio, reading magazines, or reading newspapers have higher contraceptive knowledge than those who do not; women who participate in organizations have greater contraceptive knowledge than their non-participating counterparts. The instruments explain contraceptive knowledge very well. The F statistics are 39.91, 86.74, 51.75, 17.23, and 35.42 in 1965, 1967, 1976, 1980, and 1985, respectively. All F statistics are above ten, surpassing the threshold of powerfulness for instrumental variables. The first stage indicates that mass media and social networks play crucial roles in obtaining contraceptive knowledge, consistent with the findings of previous literature.

The result of the second stage is listed in the lower panel of Table 3. After taking into account endogeneity, the signs of the coefficients on contraceptive knowledge change from positive to negative. An additional contraceptive technique known by women decreases the total number of births by $0.15,0.10,0.13,0.18$, and 0.20 in 1965,1967 , 1976, 1980, and 1985, respectively. The price effect in fertility equation is negative - the women with high education and currently working outside of the family have fewer births. The income effect in the fertility equation is positive but only reaches statistical significance in 1976. The influences of other demographic factors on fertility are similar with the findings in OLS.

\section{The Probability of Giving Birth}

This study estimates the probability of giving birth using OLS and 2SLS approach. The result of OLS is listed in Table 4. The result indicates that contraceptive knowledge has almost no effect on the likelihood of giving birth in the last year, conditional upon the accumulative live birth has been given before the previous year, except in 1967. Those who had not had any sons before the previous year yet are more likely to give birth last year than the counterparts. The result implies that married couples' preference toward sons is still existent. The younger cohorts have a higher probability of giving birth in the previous year than older cohorts. Women who are currently working outside of family have a lower probability of giving birth within the past year. Women's education is not associated with the likelihood of giving birth.

The result of 2SLS analysis is listed in Table 5. The upper panel of Table 5 presents IV result for first stage. 
Table 2 Estimation of number of live births (OLS model)

\begin{tabular}{|c|c|c|c|c|c|}
\hline & $1965(N=3662)$ & $1967(N=4871)$ & $1976(N=4678)$ & $1980(N=3852)$ & $1985(N=3817)$ \\
\hline Number of contraceptives known & $0.07 * * *$ & $0.05 * * *$ & $0.02 * *$ & $-0.02 *$ & $-0.02+$ \\
\hline No sons & $-1.49 * * *$ & $-1.64 * * *$ & $-1.15^{* * *}$ & $-0.97 * * *$ & $-0.90 * * *$ \\
\hline \multicolumn{6}{|l|}{ Age (reference: age range $38-44$ ) } \\
\hline Age range $18-22$ & $-3.95 * * *$ & $-3.75 * * *$ & N/A & $-1.97 * * *$ & $-1.78 * * *$ \\
\hline Age range $23-27$ & $-3.27 * * *$ & $-3.13 * * *$ & $-2.20 * * *$ & $-1.44 * * *$ & $-1.31 * * *$ \\
\hline Age range $28-32$ & $-2.06 * * *$ & $-2.09 * * *$ & $-1.45 * * *$ & $-0.80 * * *$ & $-0.81 * * *$ \\
\hline Age range $33-37$ & $-0.83 * * *$ & $-1.01 * * *$ & $-0.64 * * *$ & $-0.24 * *$ & $-0.37 * * *$ \\
\hline Working outside of family & $-0.25 * * *$ & $-0.17 * *$ & $-0.15 * *$ & $-0.12 * *$ & $-0.21 * * *$ \\
\hline \multicolumn{6}{|c|}{ Years of education (reference: $7-11$ years) } \\
\hline 12 years of education or above & $-0.61 * * *$ & $-0.74 * * *$ & $-0.58 * * *$ & $-0.47 * * *$ & $-0.46^{* * *}$ \\
\hline $0-6$ years of education & $0.29 * * *$ & $0.36 * * *$ & $0.37 * * *$ & $0.24 * * *$ & 0.03 \\
\hline Live in a city & $-0.66 * * *$ & $-0.22 *$ & $-0.20 * *$ & $-0.20 * *$ & $-0.22 * * *$ \\
\hline Live with parents-in-law & -0.08 & -0.02 & 0.05 & 0.05 & 0.03 \\
\hline Husband's income & N/A & -0.04 & 0.00 & -0.04 & -0.03 \\
\hline Constant & $6.11 * * *$ & $6.38 * * *$ & $4.60 * * *$ & $3.76 * * *$ & $4.03 * * *$ \\
\hline R-squared & 0.56 & 0.53 & 0.49 & 0.47 & 0.46 \\
\hline
\end{tabular}

$+P<0.10, * P<0.05, * * P<0.01, * * * P<0.001$

$N / A$ no observation in that category

Standard errors are robust and clustered in township level

Also control for ethnicity, husband's education, and township fixed effects

The result supports that mass media exposure and social networks play important roles in the acquisition of contraceptive knowledge. The instruments are powerful in predicting contraceptive knowledge.

The lower panel of Table 5 presents result for second stage. The result show that, conditional on the number of births until last year, one more contraceptive technique known prevents the likelihood of having births last year by $6,3,4,5$, and 5 percentage points in survey years of 1965 , 1967, 1976, 1980, and 1985, respectively. The more births each woman has had, the less likely she is to give birth, and the magnitude of this effect increases over time. This explains the number of births to each woman has been decreasing over time which reflects the decreasing birth rate. Women who have not had any sons remain more likely to have another birth. This shows that sex preference toward sons still exists. Younger cohorts are more likely to have births last year than older ones. Women who are currently working outside of the family are less likely to give birth. Women who currently live with parents-in-law are more likely to have given birth recently, but the coefficients are only significant in 1980 and 1985. Husband's income is positively associated with the probability of giving birth. In general, the results indicate that contraceptive knowledge reduces fertility no matter whether that fertility is measured by life-time fertility or the probability of recently having given birth.

\section{Limitation and Evaluation of Our Instrumental Variables}

The instruments of contraceptive knowledge-mass media exposure and social networks-have a strong joint influence on the obtainment of contraceptive knowledge. This study would be able to identify the effect of contraceptive knowledge on fertility as long as the exclusion restriction is valid, that is, as long as mass media exposure and social networks affect fertility only through contraceptive knowledge.

Indeed, the Sargan test of over-identifying restrictions (Sargan 1958) suggests that the instruments this study uses are valid in most of survey waves especially in the likelihood of having births equation. The $P$-values to the Sargan over identification tests are listed in Table 3 and 5. The null hypothesis that all excluded instruments are exogenous fails to be rejected in the year 1965 and 1976 for total number of live births equation, and every survey year for the likelihood of having birth equation except 1976.

However, a number of arguments still can be made to question exclusion restriction. First, mass media exposure and/or organization participation might not only expand contraceptive knowledge but also shape fertility attitudes in a way that influences fertility demand. If fertility attitudes changed through mass media exposure influence the acquisition of contraceptive knowledge, then the coefficient 
Table 3 Estimation of number of live births (2SLS model)

\begin{tabular}{lllll}
1965 & 1967 & 1976 & 1980 & 1985 \\
$(N=3662)$ & $(N=4868)$ & $(N=4678)$ & $(N=3852)$ & $(N=3817)$ \\
\hline
\end{tabular}

First stage: estimation of number of contraceptives known

Listen to radio regularly

$0.36 * * *$

Read newspapers regularly

$1.88 * * *$

$0.82 * * *$

$0.51 * * *$

$0.21 *$

$0.30 * * *$

Watch TV regularly

N/A

$1.59 * * *$

$1.18 * * *$

$0.83 * * *$

$1.07 * * *$

Read magazines regularly

N/A

$0.72 * * *$

$0.83 * * *$

$0.29 * *$

$-0.03$

Join organizations

N/A

N/A

$0.89 * * *$

$0.84 * * *$

$0.54 * * *$

F statistics

39.91

N/A

$0.50 * * *$

$0.41 * *$

$0.52 * * *$

Second stage: estimation of number of live births

Number of contraceptives known

$\begin{array}{ll}-0.15^{* * * *} & -0.10^{* *} \\ -1.68 * * * & -1.76^{* * *} \\ -4.09 * * * & -3.86^{* * *} \\ -3.31 * * * & -3.16^{* * *} \\ -1.98^{* * *} & -2.04 * * * \\ -0.76 * * * & -0.96 * * * \\ -0.24 * * & -0.13 * \\ -0.19 & -0.54 * * * \\ -0.02 & 0.15+ \\ -0.67 * * & -0.11 \\ -0.12+ & -0.06 \\ \text { N/A } & 0.07 \\ 0.50 & 0.50 \\ 0.4707 & 0.0826\end{array}$

51.75

17.23

35.42

No son

Age rage 18-22 (base: 38-44)

Age range 23-27

Age rage 28-32

Age range 33-37

Working outside of family

Education years 12 or above (base: 7-11)

Education years 0-6

Living in a city

Live with parents-in-law

Husband's income

R-squared

$-0.13 * * *$
$-1.24 * * *$
N/A
$-2.25 * * *$
$-1.45 * * *$
$-0.58 * * *$
$-0.13 * *$
$-0.33 * * *$
$0.20 * * *$
-0.06
0.01
$0.03 *$
0.43
0.1415

$-0.18^{* * *}$

$-0.20 * * *$

$-0.92 * * *$

$-1.76 * * *$

$-2.07 * * *$

$-1.20 * * *$

$-1.46 * * *$

$-0.72 * * *$

$-0.79 * * *$

$-0.33 * * *$

$-0.22 * * *$

$-0.18 * * *$

Over-identification test $(P$-value $)$

$-0.11 * *$

$-0.20 * *$

$-0.25 * * *$

$-0.23 *$

0.06

$-0.06$

$-0.17 *$

0.05

0.04

$0.05 \quad 0.04$

$0.40 \quad 0.36$

$+P<0.10, * P<0.05, * * P<0.01, * * * P<0.001$

Standard errors are robust and clustered in township level. N/A indicates no information in that category. Also control for ethnicity, husband's education, and township fixed effects. The first stage equation also controls for other individual characteristics [see Eq. (2)]

Table 4 Estimation of the probability of having births last year (OLS model)

\begin{tabular}{|c|c|c|c|c|c|}
\hline & $\begin{array}{l}1965 \\
(N=3564)\end{array}$ & $\begin{array}{l}1967 \\
(N=4776)\end{array}$ & $\begin{array}{l}1976 \\
(N=4460)\end{array}$ & $\begin{array}{l}1980 \\
(N=3788)\end{array}$ & $\begin{array}{l}1985 \\
(N=3614)\end{array}$ \\
\hline Number of contraceptives known & -0.00 & $-0.01 *$ & 0.00 & 0.00 & $0.00+$ \\
\hline No son & $0.09 * * *$ & $0.18 * * *$ & $0.12 * * *$ & $0.08 * *$ & $0.11 * * *$ \\
\hline Total live births until last year & -0.00 & -0.00 & $-0.04 * * *$ & $-0.09 * * *$ & $-0.09 * * *$ \\
\hline Age range $18-22$ (base: age $37-44$ ) & $0.41 * * *$ & $0.43 * * *$ & N/A & $0.20 * * *$ & $0.26 * * *$ \\
\hline Age range $23-27$ & $0.52 * * *$ & $0.49 * * *$ & $0.31 * * *$ & $0.20 * * *$ & $0.26 * * *$ \\
\hline Age range $28-32$ & $0.39 * * *$ & $0.33 * * *$ & $0.28 * * *$ & $0.09 * * *$ & $0.13 * * *$ \\
\hline Age range $33-37$ & $0.15^{* * *}$ & $0.13 * * *$ & $0.15 * * *$ & -0.00 & 0.00 \\
\hline Working outside of family & $-0.10 * * *$ & $-0.05 * *$ & $-0.13 * * *$ & $-0.09 * * *$ & $-0.07 * * *$ \\
\hline Education years 12 or above (base: $7-11$ ) & 0.00 & -0.02 & 0.03 & -0.01 & 0.00 \\
\hline Education years $0-6$ & -0.00 & 0.02 & 0.02 & -0.01 & 0.01 \\
\hline Living in a city & $-0.06^{*}$ & -0.01 & -0.03 & -0.03 & $-0.03+$ \\
\hline Live with parents-in-law & 0.01 & 0.01 & 0.02 & $0.04 * *$ & $0.04 * *$ \\
\hline Husband's income & N/A & -0.02 & -0.00 & 0.02 & $0.02+$ \\
\hline Constant & $0.08+$ & $0.31 * * *$ & $0.27 * * *$ & $0.34 * * *$ & $0.23 * * *$ \\
\hline Observations & 3564 & 4776 & 4460 & 3788 & 3614 \\
\hline
\end{tabular}

$+P<0.10, * P<0.05, * * P<0.01, * * * P<0.001$

Standard errors are robust and clustered in township level. N/A indicates no information in the category. Also control for ethnicity, husband's education, and city/county fixed effects 
Table 5 Estimation of the probability of having birth last year (2SLS model)

\begin{tabular}{|c|c|c|c|c|c|}
\hline & $\begin{array}{l}1965 \\
(N=3564)\end{array}$ & $\begin{array}{l}1967 \\
(N=4773)\end{array}$ & $\begin{array}{l}1976 \\
(N=4460)\end{array}$ & $\begin{array}{l}1980 \\
(N=3788)\end{array}$ & $\begin{array}{l}1985 \\
(N=3614)\end{array}$ \\
\hline \multicolumn{6}{|c|}{ First stage: number of contraceptives known } \\
\hline Listen to the radio & $0.38 * * *$ & $0.84 * * *$ & $0.50 * * *$ & $0.20 *$ & $0.29 * * *$ \\
\hline Read newspapers & $1.9 * * *$ & $1.63 * * *$ & $1.18 * * *$ & $0.81 * * *$ & $1.07 * * *$ \\
\hline Watch TV & N/A & $0.70 * * *$ & $0.84 * * *$ & $0.29 * *$ & -0.03 \\
\hline Read magazines & N/A & N/A & $0.91 * * *$ & $0.84 * * *$ & $0.53 * * *$ \\
\hline Join Organization & N/A & N/A & $0.49 * * *$ & $0.43 *$ & $0.52 * *$ \\
\hline F statistics & 43.21 & 91.49 & 52.70 & 16.58 & 34.21 \\
\hline \multicolumn{6}{|c|}{ Second stage: whether having live births last year } \\
\hline Number of contraceptives known & $-0.06 * * *$ & $-0.03 * * *$ & $-0.04 * * *$ & $-0.05 * * *$ & $-0.05 * * *$ \\
\hline No sons & $0.05 *$ & $0.16^{* * *}$ & $0.10 * * *$ & $0.08 * * *$ & $0.10 * * *$ \\
\hline Number of live births until last year & 0.01 & -0.00 & $-0.04 * * *$ & $-0.10 * * *$ & $-0.09 * * *$ \\
\hline Age range $18-22$ (base: $38-44$ ) & $0.43 * * *$ & $0.44 * * *$ & N/A & $0.14 * * *$ & $0.25 * * *$ \\
\hline Age range $23-27$ & $0.55^{* * *}$ & $0.50 * * *$ & $0.31 * * *$ & $0.18 * * *$ & $0.28 * * *$ \\
\hline Age range $28-32$ & $0.44 * * *$ & $0.34 * * *$ & $0.29 * * *$ & $0.09 * * *$ & $0.15 * * *$ \\
\hline Age range $33-37$ & $0.19 * * *$ & $0.15^{* * *}$ & $0.16 * * *$ & 0.01 & 0.01 \\
\hline Working outside of family & $-0.10 * * *$ & $-0.04 *$ & $-0.12 * * *$ & $-0.08 * * *$ & $-0.06 * * *$ \\
\hline Education years $12+$ (base: 7-11) & $0.12 *$ & 0.02 & $0.10 * *$ & $0.06^{*}$ & $0.08 * *$ \\
\hline Education years $0-6$ & $-0.09 * *$ & -0.01 & -0.03 & $-0.07 * *$ & $-0.08 * *$ \\
\hline Live in a city & $-0.06+$ & 0.00 & 0.01 & -0.02 & 0.02 \\
\hline Live with parents in law & 0.00 & 0.00 & 0.01 & $0.04 * *$ & $0.05 * * *$ \\
\hline Husband's income & N/A & 0.00 & 0.00 & $0.05 * *$ & $0.04 * * *$ \\
\hline Over-identification test ( $P$-value) & 0.9067 & 0.4113 & 0.0670 & 0.1580 & 0.6382 \\
\hline
\end{tabular}

$+P<0.10, * P<0.05, * * P<0.01, * * * P<0.001$

Standard errors are robust and clustered in township level. N/A indicates no information in that category. Also control for ethnicity, husband's education, and township fixed effects. The first stage equation also controls for other individual characteristics [see Eq. (5)]

on contraceptive knowledge in the second stage of the 2SLS approach does not solely reflect the effect of contraceptive knowledge on fertility; it also reflects the couple's attitudes about a desired number of children and/or the sex composition of their family. Women who are regularly exposed to mass media or who have a wider social network are more likely to have access to family planning messages on the benefits of having fewer children and access to knowledge of modern contraceptive techniques than women without that exposure. If contraceptive attitudes and knowledge are correlated, the coefficient on contraceptive knowledge in the fertility equation might not only reflect the contraceptive knowledge but also attitudes which lead to over-estimate the effect of contraceptive knowledge.

Another argument concerning the validity of the instrumental variables used in this paper is based upon a hypothetical unobserved characteristic which may collectively drive contraceptive knowledge, mass media exposure and organization participation. Women selected to the group with regular exposure to mass media and/or with wider social networks are different from the group of women who are not. They might be different in observable ways. For example, women who are regularly exposed to mass media and/or have larger social networks might have a higher level of education, be younger, and be wealthier. On the other hand, it is possible they might be different in unobservable ways. For example, women with regular mass media exposure and wider social networks might be more open to new information than those with less exposure. These observable and unobservable characteristics might influence the fertility decision. While this study controls for differences in observable characteristics, it does not control for differences in unobservable characteristics. If there is an unobservable difference between the two groups in the case described above, the coefficient on contraceptive knowledge might be over estimated.

\section{Conclusion}

Taiwan's family planning programs, enacted in 1964, aimed to decrease women's fertility and control population growth. The programs changed married couples' fertility demand by educating them about population growth issues, 
and by disseminating knowledge of modern contraceptive methods. This paper examines the effect of contraceptive knowledge on fertility, and focuses on the period when the family planning programs were enacted. In order to take into consideration the endogeneity of contraceptive knowledge in the fertility equation, this study uses the instrumental variable approach. Mass media exposure and social networks are proxies for acquired contraceptive knowledge. The empirical results indicate that contraceptive knowledge significantly reduces fertility, whether fertility is measured as life-time fertility or the probability of giving birth.

Besides, this paper found that mass media exposure and social networks play important roles in obtaining knowledge of modern contraceptive techniques. Women, who regularly watch TV, listen to the radio, or read newspapers and magazines are more likely to be exposed to contraceptive-related information and hence have more knowledge of contraceptives. Similarly, women who participate in women's organizations are more likely to obtain contraceptive information through word-of-mouth communication.

Price and income are the fundamental factors in the demand functions. In the fertility equation, women's working status and years of schooling, which can serve as proxies for the price (opportunity cost) of having children are negatively associated with fertility; income (husband's income) is positively associated but not statistically significant with the number of births. Demographic characteristics, such as ethnicity, age cohorts, and residency with parents-in-law are associated with fertility decisions. The preference toward sons is still existent in the society. Women who haven't had any sons are more likely to give birth, conditional upon the number of babies they have already had.

There is a large body of literature investigating the relationship between knowledge and behaviors, covering different fields of interests, such as product consumption, risky behaviors, and health outcomes. Very few such studies focus on the relationship between contraceptive knowledge and fertility decision. This paper investigates the effect of contraceptive knowledge on fertility, and helps to shed new light on the relationship between knowledge and behavior.

Open Access This article is distributed under the terms of the Creative Commons Attribution Noncommercial License which permits any noncommercial use, distribution, and reproduction in any medium, provided the original author(s) and source are credited.

\section{References}

Aggarwal, R., \& Rous, J. (2006). Awareness and quality of knowledge regarding HIV/AIDS among women in India. The Journal of Development Studies, 42(3), 371-401.

Barber, J., \& Axinn, W. (2004). New ideas and fertility limitation: The role of mass media. Journal of Marriage and Family, 66, $1180-1200$.
Behrman, J., Kohler, H. P., \& Watkins, S. C. (2002). Social networks and changes in contraceptive use over time: Evidence from a longitudinal study in rural Kenya. Demography, 39(4), 713-738.

Braunder-Otto, S., Axinn, W. G., \& Ghimire, D. J. (2007). The spread of health services and fertility transition. Demography, 44(4), 747-770.

Chang, M. C., Freedman, R., \& Sun, T. H. (1981). Trends in fertility, family size preferences, and family planning practice: Taiwan, 1961-80. Studies in Family Planning, 12(5), 211-228.

Chang, M. C., Freedman, R., \& Sun, T. H. (1987). Trends in fertility, family size preferences, and family planning practices in Taiwan, 1961-85. Studies in Family Planning, 18(6), 320-337.

Chang, H. H., Nayga, R. M., Chan, K. C. (2010). Gendered analyses of nutrient deficiencies among the elderly. Journal of Family and Economic Issues. doi:10.1007/s10834-010-9241-0.

Chu, H. (1966). Family planning in Taiwan, Republic of China, 1965-1966. Taichung: Taiwan Population Studies Center.

Coombs, L. C. (1973). Problems of contamination in panel surveys: A brief report on an independent sample, Taiwan, 1970. Studies in Family Planning, 4(10), 257-261.

De Walque, D. (2007). How does the impact of an HIV/AIDS information campaign vary with educational attainment? Evidence from Rural Uganda. Journal of Development Economics, 84(2), 686-714.

Edmeades, J. (2008). The legacies of context: Past and present influences on contraceptive choice in Nang Rong, Thailand. Demography, 45(2), 283-302.

Freedman, R., \& Takeshita, J. Y. (1969). Family planning in Taiwan: An experiment in social change. Princeton: Princeton University Press.

Freedman, R., Coombs, L. C., Chang, M., \& Sun, T. (1974). Trends in fertility, family size preferences, and practice of family planning: Taiwan, 1965-1973. Studies in Family Planning, 5(9), 270-288.

Freedman, R., Chang, M. C., \& Sun, T. H. (1994). Taiwan's transition from high fertility to below-replacement levels. Studies in Family Planning, 25(6), 317-331.

Gertler, P. J., \& Molyneaux, J. W. (1994). How economic development and family planning programs contributed to reduce Indonesian fertility. Demography, 31(1), 33-63.

Hondroyiannis, G. (2010). Fertility determinants and economic uncertainty: An assessment using European panel data. Journal of Family and Economic Issues, 31, 33-50.

Ippolito, P., \& Mathios, A. (1990). Information, advertising and health choices: A study of the cereal market. The Rand Journal of Economics, 21(3), 459-480.

Kan, K., \& Tsai, W. D. (2004). Obesity and risk knowledge. Journal of Health Economics, 23, 907-934.

Kenkel, D. S. (1991). Health behavior, health knowledge, and schooling. The Journal of Political Economy, 99(2), 287-305.

Lapham, R. J., \& Mauldin, W. P. (1985). The influences of organized family planning programs. Studies in Family Planning, 16(3), $117-137$.

Miller, G. (2009). Contraception as development? New evidence from family planning in Colombia. The Economic Journal, 120, 709-736.

Montgomery, M., \& Casterline, J. (1993). The diffusion of fertility control in Taiwan: Evidence from pooled cross-section timeseries models. Population Studies, 47, 457-479.

Pritchett, L. H. (1994). Desired fertility and the impact of population policies. Population and Development Review, 20(1), 1-55.

Rosenzweig, M. R., \& Schultz, T. P. (1989). Schooling, information and nonmarket productivity: Contraceptive use and its effectiveness. International Economic Review, 30(2), 457-477.

Rosenzweig, M. R., \& Wolpin, K. I. (1986). Evaluating the effects of optimally distributed public programs: Child health and family planning interventions. American Economic Review, 76(3), $470-482$. 
Sargan, J. (1958). The estimation of economic relationships using instrumental variables. Econometrica, 26(3), 393-415.

Schultz, T. P. (1994). Human capital, family planning, and their effects on population growth. American Economic Review Papers and Proceedings, 84(2), 255-260.

Schultz, T. P. (2005). Effects of fertility decline on family well-being: Opportunities for evaluating population programs. New Haven: Mimeo, Yale University.

Shreffler, K. M., Pirretti, A. E., \& Drago, R. (2010). Work-family conflict and fertility intentions: Does gender matter? Journal of Family and Economic Issues, 31, 228-240.

Sinha, N. (2005). Fertility, child work, and schooling consequences of family planning programs: Evidence from an experiment in rural Bangladesh. Economic Development and Cultural Change, 54(1), 97-128.

Sun, T., Lin, H., \& Freedman, R. (1978). Trends in fertility, family size preferences, and family planning practice: Taiwan, 1961-76. Studies in Family Planning, 9(4), 54-70.
Variyam, J., Blaylock, J., \& Smallwood, D. (1999). Information, endogeneity, and consumer health behavior: Application to dietary intakes. Applied Economics, 31, 217-226.

\section{Author Biography}

Kai-Wen Cheng is a postdoctoral fellow in the Center for Tobacco Control Research and Education at University of California, San Francisco. Her research interests lie in the interaction of health policy, health behaviors, and family roles with the special focus on fertility and cigarette smoking. She holds a Ph.D. in Policy Analysis and Management from Cornell University. 